\title{
Propagule dispersal and larval patch cohesiveness in a Mediterranean coastal fish
}

\author{
Antonio Calò ${ }^{1, *}$, Antonio Di Franco ${ }^{2}$, Giuseppe E. De Benedetto ${ }^{3}$, Antonio Pennetta ${ }^{3}$, \\ Ángel Pérez-Ruzafa ${ }^{1}$, José Antonio García-Charton ${ }^{1}$ \\ ${ }^{1}$ Departamento de Ecología e Hidrología, Universidad de Murcia, Murcia 30100, Spain \\ ${ }^{2}$ Université Nice Sophia Antipolis, CNRS, FRE 3729 ECOMERS, Parc Valrose 28, Avenue Valrose, Nice 06108, France \\ ${ }^{3}$ Laboratorio di Spettrometria di massa analitica ed isotopica, Dipartimento di Beni Culturali, University of Salento, \\ Lecce 73100 , Italy
}

\begin{abstract}
The assessment of fish dispersal is fundamental for both conservation and management of fishery resources as it provides crucial information for the establishment of more effective marine protected areas (MPAs) and networks of MPAs. In this study, we investigated the elemental composition of otoliths in early life stages of the saddled sea bream Oblada melanura (Linnaeus, 1758) (Perciformes: Sparidae) in order to obtain information on its propagule (egg and larva) dispersal in the south-western Mediterranean Sea. Specifically, using pre-settlement individuals we investigated (1) larval patch cohesiveness during the last phase of larval life; and with early post-settlement individuals we investigated (2) the number of potential natal sources, and (3) propagule dispersal distances. Results indicated that different larval patches can merge in the pelagic environment after having travelled separately for some days. In total, 7 natal sources were found to replenish, with different proportions, almost all sampling sites along a stretch of coastline of $\sim 180 \mathrm{~km}$, suggesting that propagule dispersal can extend at least up to $\sim 90 \mathrm{~km}$. This information provides important insights for understanding fish dispersal processes and supports the appropriate establishment of spatially explicit conservation strategies such as MPAs and MPA networks in the south-western Mediterranean Sea.
\end{abstract}

KEY WORDS: Propagule dispersal - Natal origins - Patch cohesiveness - Saddled sea bream Mediterranean Sea

Resale or republication not permitted without written consent of the publisher

\section{INTRODUCTION}

Dispersal is the process by which organisms distribute themselves, actively or passively, affecting patterns of connectivity (i.e. sub-populations linked through the exchange of individuals), meta-population dynamics and ultimately, species persistence (Cote et al. 2010, Shima \& Swearer 2010). The study of dispersal patterns is of paramount importance for marine biodiversity conservation and fisheries management as it provides vital information for the establishment of effective marine protected areas (MPAs) and networks of MPAs (Grüss et al. 2011, Green et al. 2015). In many coastal fish with bipartite life cycles (i.e. composed of a larval and a juvenile/adult phase), the life stages following settlement (i.e. when the pelagic larval phase ends with metamorphosis into the juvenile stage) are usually relatively sedentary, so that species dispersal potential is mostly determined by the propagule (i.e. egg and larva) phase (Leis 2015, but see Di Franco et al. 2015). Despite the huge effort currently being undertaken, the empirical measure of propagule dispersal is still extremely challenging for fish ecologists. This is due to several issues, for example, the difficulty in marking small planktonic larvae and/or recapturing them (given their high mortality rates) (Barbee \& Swearer 2007, Fontes et al. 2009). 
Recently, a number of studies have been conducted using natural environmental markers to investigate fish natal origins and evaluate species dispersal capacity (see Leis et al. 2011, Calò et al. 2013 for reviews). Otoliths are particularly useful as they record the chemical characteristics of the surrounding environment experienced by fishes during all life phases (Barbee \& Swearer 2007). Otoliths grow by continuous deposition of layers of calcium carbonate (mainly aragonite) in a protein matrix (Campana 1999). During deposition, trace elements from the ambient water can substitute for calcium, remaining permanently in the matrix (Campana 1999). The physical and chemical characteristics of the environment (primarily temperature, salinity and trace element concentrations) influence the incorporation rates of some specific elements (e.g. Sr and $\mathrm{Ba}$ ) into the otolith matrix (Campana 1999, Walther \& Thorrold 2006, Barnett-Johnson et al. 2008, Muhlfeld et al. 2012). Variations in the elemental composition of otoliths can therefore be used to discriminate larval groups that have experienced different environmental conditions, and to obtain information on important early life history traits such as the number of potential natal sources, larval dispersal distances and pathways (Hamilton et al. 2008, Fontes et al. 2009, Shima \& Swearer 2010, Di Franco et al. 2012, Miller et al. 2014, Shima et al. 2015, but see also Berumen et al. 2010).

Analysis of the chemical profile from the otolith edge toward its core provides information on the different environmental conditions previously experienced by a larva (Sandin et al. 2005). The comparison of otolith chemical profiles of larvae originating from the same patch (i.e. an aggregation of larvae) can be used to investigate the consistency of the patch during the pelagic phase (i.e. its cohesiveness). In fact, if larvae travelled together to the sampling site, their otoliths would have the same chemical profile, otherwise, the chemical profiles would be different (Shima \& Swearer 2009, Ben-Tzvi et al. 2012). Knowledge of the ontogenetic cohesiveness of a larval patch can provide important insights into post-settlement demographic dynamics (Shima et al. 2015) as different larval trajectories, potentially shaped by a variable dispersal environment, can have important implications for the post-settlement persistence of the larval patch (Shima \& Swearer 2009, 2010, Shima et al. 2015).

Analysis of the chemical composition of otolith cores (i.e. the inner portion of otoliths that forms during embryogenesis) allows the assessment of the number of potential sources of propagules that sup- ply different settlement sites along a given stretch of coastline (Ruttenberg et al. 2008). With this information, it is possible to infer the spatial scale over which propagule dispersal takes place, considering the distance among sites that are replenished by a single natal source and the number of potential sources within the sampled area (Standish et al. 2008, Di Franco et al. 2012, 2015).

In this study, we investigated geochemical signatures in the otoliths of early life stages of the saddled sea bream Oblada melanura (Linnaeus, 1758) (Perciformes: Sparidae) in order to obtain information on its propagule dispersal characteristics in the southwestern Mediterranean Sea. Specifically, we used pre-settlement individuals of $O$. melanura to investigate (1) the cohesiveness of larval patches during the last phase of the larval life; and early post-settlement individuals to investigate (2) the number of potential natal sources and post-settler replenishment patterns in our study area and (3) propagule dispersal distances. This information can provide important insights for fish dispersal processes and contribute to the proper establishment of spatially explicit conservation tools such as MPAs and MPA networks.

\section{MATERIALS AND METHODS}

\section{Study area and sampling design}

The study was conducted along the south-east coast of Spain (SW Mediterranean Sea). This area is particularly relevant from a conservation perspective as it hosts an important biodiversity hotspot in the Western Mediterranean Sea (Calvin-Calvo et al. 1999). Oblada melanura was chosen as a model species as it is widely distributed and generally abundant in Mediterranean coastal habitats (Bauchot \& Hureau 1986, García-Charton et al. 2004) and has a relatively high commercial value for artisanal and recreational fisheries (Harmelin-Vivien et al. 1995, Lloret et al. 2008, Félix-Hackradt et al. 2014). This sedentary fish forms large shoals in littoral waters above rocky bottoms and Posidonia beds up to $30 \mathrm{~m}$ deep (Bauchot \& Hureau 1986). Along the southeastern Spanish coast, reproduction occurs between June and July with the majority of spawning output released during a narrow temporal window of 2 to 3 wk (Félix-Hackradt et al. 2013). After travelling in the pelagic environment for $\sim 2$ wk (Raventós \& Macpherson 2001), larvae settle in shallow water habitats (depth of $2 \mathrm{~m}$ or less) characterized by shadowed overhangs and steep rocks (Bussotti \& Guidetti 2011, 
Fig. 1. Study area where Oblada melanura were sampled; inset shows location along the southeast coast of Spain. Black dots: sampling sites (numbered progressively from the northernmost to the southernmost) where post-settler O. melanura individuals were collected; black squares: sampling sites where light traps were deployed to capture pre-settlers. Rectangles outlined with dashed lines represent zones encompassing collection sites: south Alicante province (SAP), central Murcia region (CMR) and west Murcia region (WMR). Pie charts indicate the proportion of post-settlers belonging to the each natal source for each zone (see 'Results'). Dashed grey line: the assumed position of the Cabo de Palos-Oran front (see 'Discussion')

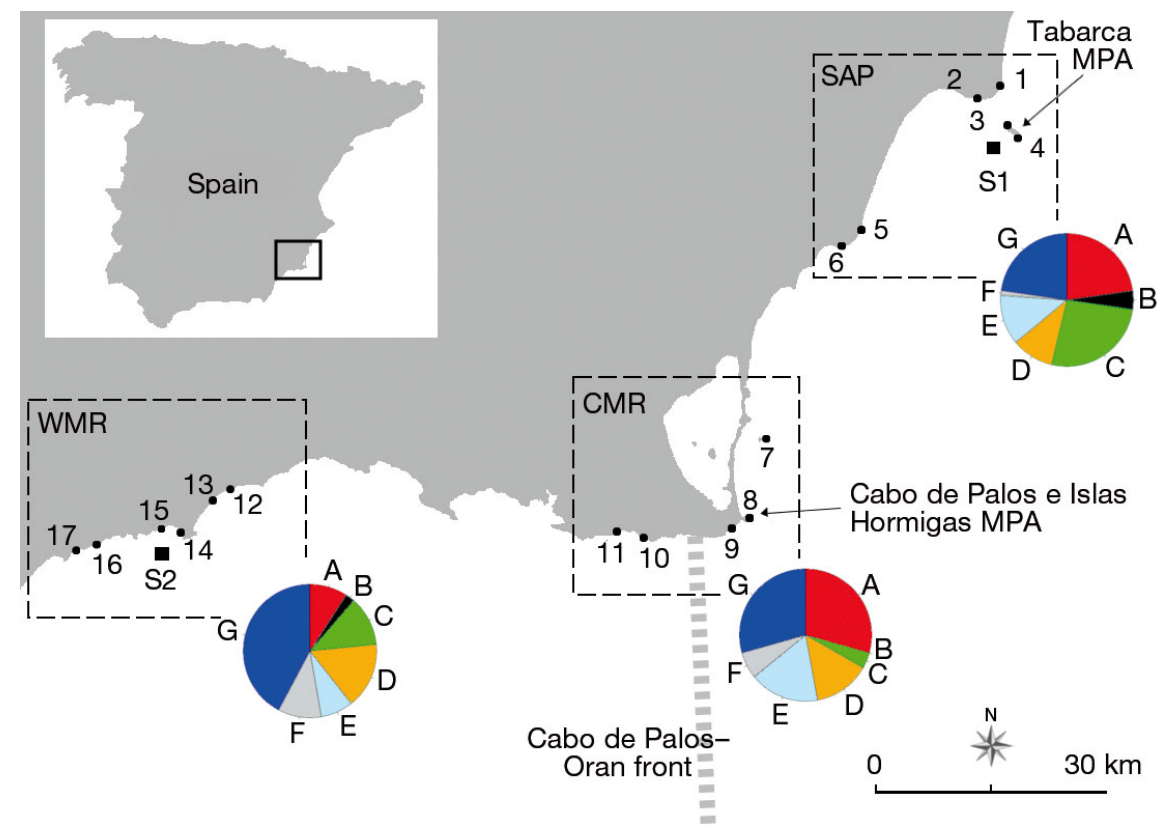

Félix-Hackradt et al. 2014). After settlement, small groups of juveniles actively aggregate in larger shoals, finally recruiting into the adult population (Kiparissis et al. 2008).

We investigated larval patch cohesiveness using late-stage larvae (i.e. pre-settlers) of $O$. melanura. Specimens were caught using light-traps during July 2013. July was chosen because it is the month with the highest larval supply recorded along the study area coast (Félix-Hackradt et al. 2013). Six light-traps were deployed at each of 2 sites (Sites S1 and S2; Fig. 1), located $150 \mathrm{~km}$ apart. Light-traps were deployed in transects running parallel to the coast, $\sim 200 \mathrm{~m}$ apart to avoid interference due to photo-attraction, and individually moored with a buoy at 20 to $30 \mathrm{~m}$ depth depending on how close the sampling site was to the coast (distance ranged from 0.3 to $0.8 \mathrm{~km}$ ). Three light-trap samples (T1, T2 and T3) from the northernmost site (Site S1) sampled during the same night, and 1 light-trap sample (T4) from the southernmost site (Site S2), collected during the following sampling night, contained between 8 and 11 pre-settlers each; these were processed in the laboratory. None of the other light-trap samples were included in successive analyses because they contained only 1 or 2 individuals, and therefore it was impossible to investigate any inter-individual variability in dispersal for the assessment of patch cohesiveness.

With the aim of investigating the number of potential natal sources and propagule dispersal distances of $O$. melanura in the study area, early postsettlement individuals were sampled in July 2013 after the peak of settlement. Post-settlers were collected from 17 sites ( $1 \mathrm{~km}$ stretches of coastline), scattered among 3 zones (stretches of $30 \mathrm{~km}$ of coastline), as follows: from north to south, southern Alicante province (Zone SAP, 6 sites), central Murcia region (Zone CMR, 5 sites) and western Murcia region (Zone WMR, 6 sites) (Fig. 1). Zones SAP and CMR contain 2 effective MPAs: Tabarca MPA and Cabo de Palos e Islas Hormigas MPA (Fig. 1). At each site, 11 to 15 post-settlers were collected in shallow waters ( $<2 \mathrm{~m}$ depth), using a hand net during snorkeling. All specimens were euthanized by immersing them in a seawater solution with a few drops of $96 \%$ alcohol to minimize suffering (Leary et al. 2013), and, after cessation of opercula movements, were preserved in $70 \%$ ethanol.

\section{Otolith preparation and analysis}

In the laboratory, total length (TL) for each pre- and post-settler individual was measured to the nearest $0.1 \mathrm{~mm}$. The right sagittal otolith was removed from each specimen, cleaned of soft tissue using plastic pins and rinsed with ultra-pure water $\left(18.2 \mathrm{M} \Omega \mathrm{cm}^{-1}\right)$. Otoliths were then mounted, sulcus side up, onto a glass slide using Crystalbond ${ }^{\mathrm{TM}}$ thermoplastic adhesive. Otoliths were polished with 3 and $1 \mu \mathrm{m}$ Imperial lapping film through the nucleus. The age of each pre- and post-settler individual was determined by analysing daily micro-increment formation (growth rings) (Green et al. 2009). Otoliths were then rinsed 
in an ultrasonic bath for 10 min with ultra-pure water in order to remove surface contamination.

Elemental analysis was performed using a Thermo Elemental X series II inductively coupled plasma mass spectrometer (ICP-MS) coupled to a New-Wave Research UP213 with an aperture imaging laser ablation (LA) system. Otolith sections were viewed remotely on a computer screen where the area for ablation was selected. The laser was focused on the sample surface and fired through the microscope's objective lens. Helium gas was flushed into the ablation cell to reduce the deposition of ablated aerosols and to improve signal intensities (see Giannossa et al. 2015 for further details on system setup). The ablated aerosol was then mixed with Argon before entering the ICP torch.

Otoliths of pre-settlers (TL: 8.6 to $10.7 \mathrm{~mm}$; mean age: $11.4 \mathrm{~d}$ ) were analysed to investigate larval patch cohesiveness. Specifically, we compared the variability in otolith chemical profiles among individuals from the same light-trap sample (here considered as a larval patch). Pre-settler otoliths were analysed through a series of 7 laser spots, following the major axis of the sagitta, and positioning each spot on a different daily growth ring from the edge of the otolith (corresponding to the otolith ring laid down during the sampling day) to the seventh last growth ring. In this way, for each pre-settler we obtained the chemical profile of the last $7 \mathrm{~d}$ of larval life. The earliest days of life were not considered since they could have added an additional source of variation (ontogenetic), masking or confounding the spatial variability of otolith chemical signatures on which the patch cohesiveness analysis was based (see 'Data analysis' below for the complete rationale of the statistical method). The mean age of $O$. melanura individuals sampled by light traps was $\sim 11 \mathrm{~d}$, thus we confidently excluded the first 3 to $4 \mathrm{~d}$ after hatching from the analysis, which corresponds to the yolk sack phase of the species (Antolovi et al. 2010). Spot size was set to $15 \mu \mathrm{m}$ in order to fit it with the width of the daily rings. Each spot run consisted of a $42 \mathrm{~s}$ acquisition: $10 \mathrm{~s}$ blank to correct for background, $2 \mathrm{~s}$ of pre-ablation to remove surface contamination (laser at $30 \%$ power), $10 \mathrm{~s}$ ablation and $20 \mathrm{~s}$ for washout.

Otoliths of post-settlers (TL: 11.3 to $25.3 \mathrm{~mm}$; mean age: $29.2 \mathrm{~d}$ ) were used to obtain information on the number of potential natal origins and larval dispersal distances of $O$. melanura. Post-settler otoliths were analysed in 2 different regions: the core and the edge. The elemental composition of the core was investigated to obtain information about natal origins, and was analysed through 3 vertical pits $30 \mu \mathrm{m}$ in diameter (approximate size of the core) and $10 \mu \mathrm{m}$ deep. The otolith edge was investigated to quantify recent elemental incorporation (i.e. material laid down just before capture) that was later tested for site discrimination (see 'Data analysis' below) and to account for within-otolith variability (Di Franco et al. 2012, 2014). The edge portion was analysed by 3 horizontal pits using the same laser spot dimensions as previously specified. Each spot run consisted of $62 \mathrm{~s}$ acquisition: $25 \mathrm{~s}$ blank to correct for background (which was subtracted from each sample), 2 s of preablation to remove surface contamination (laser at $30 \%$ power), $10 \mathrm{~s}$ ablation and $25 \mathrm{~s}$ for washout. Otoliths were placed in the ablation chamber in groups of 6, randomly selected from the 17 sampling sites, to prevent sample batch bias.

For both pre- and post-settlers' otoliths, instrumental precision was maintained by analysing solid glass standard material from the National Institute of Standards and Technology (NIST 610 and NIST 612) every 6 samples, carrying out a linear interpolation between the 2 consecutive sets of standards. Calcium was used as an internal standard to take into account variation in ablation and aerosol efficiency. All 7 elements analysed $\left({ }^{7} \mathrm{Li},{ }^{24} \mathrm{Mg},{ }^{45} \mathrm{Mn},{ }^{66} \mathrm{Zn},{ }^{88} \mathrm{Sr},{ }^{138} \mathrm{Ba}\right.$, and ${ }^{208} \mathrm{~Pb}$ ) were expressed as ratios relative to ${ }^{44} \mathrm{Ca}$. Detection limits were calculated from the concentration of analyte, yielding a signal equivalent to $3 \times$ the standard deviation of the blank signal for each element (Table 1). Recoded values of $\mathrm{Li}, \mathrm{Mn}, \mathrm{Zn}$ and $\mathrm{Pb}$ were consistently below detection limits, and thus were excluded from the analysis.

Table 1. Estimates of precision, accuracy and limits of detection (LOD) for the otoliths of Oblada melanura post- and pre-settlers based on solid glass standard material from the National Institute of Standards and Technology (NIST 610 and NIST 612). Values for \% relative standard deviation (RSD) and $\%$ accuracy are dimensionless

\begin{tabular}{|lcrccc|}
\hline $\begin{array}{l}\text { Element } \\
\text { ratio }\end{array}$ & $\begin{array}{c}\text { NIST 610 } \\
\text { \% RSD }\end{array}$ & $\begin{array}{c}\text { NIST 612 } \\
\text { \% RSD }\end{array}$ & $\begin{array}{c}\text { NIST 610 } \\
\text { \% Accuracy }\end{array}$ & $\begin{array}{c}\text { NIST 612 } \\
\text { \% Accuracy }\end{array}$ & $\begin{array}{c}\text { LOD } \\
\left(\mathrm{mmol} \mathrm{mol}^{-1} \text { ) }\right.\end{array}$ \\
\hline Post-settlers & & & & & \\
Mg:Ca & 9.8 & 11.1 & 84 & 92 & 0.03852 \\
Sr:Ca & 7.8 & 8.3 & 115 & 98 & 0.00148 \\
Ba:Ca & 7.1 & 9.4 & 91 & 89 & 0.00066 \\
Pre-settlers & & & & & \\
Mg:Ca & 6.6 & 14.4 & 98 & 106 & 0.04568 \\
Sr:Ca & 7 & 9.3 & 98 & 93 & 0.01441 \\
Ba:Ca & 6.1 & 7 & 98 & 82 & 0.00076 \\
\hline
\end{tabular}




\section{Data analysis}

Otolith elemental concentration data were converted to molar concentrations and $\log (x+1)$ transformed.

Larval patch cohesiveness was investigated by analysing the within-patch (i.e. light-trap) variability in pre-settler otolith chemical profiles. In particular, we compared the chemical composition of otoliths day by day, grouping together chemical data from chronologically homologous rings of different otoliths (i.e. rings corresponding to the same day of life for all fish). Based on the proviso that the chemical composition of otoliths is similar for individuals of the same age and population that experienced the same environmental conditions, we hypothesised that the variability of the chemical composition for individuals caught in the same light-trap would have increased from the first ring analysed (i.e. most recent ring, laid down immediately before sampling) toward the last ring analysed (i.e. $6 \mathrm{~d}$ before sampling) in the case in which fish travelled different dispersal pathways (i.e. starting from different sites and then reaching the same light-trap). Otherwise, if pre-settlers travelled together to the light-trap site where they were collected, similar variability would be found between the edge and previous rings of the otolith (representing days of larval life). In order to perform the analysis, otolith chemical data were normalised and grouped by the ring analysed from the last (1, the edge of the otolith) to the seventh last (7). The different light-traps samples were considered separately. Individual deviations from the centroids for each otolith ring, across individuals from the same lighttrap, were then calculated using PERMDISP. Finally, centroid distances were analysed through a permutational multivariate analysis of variance (PERMANOVA), in which light-trap (LT) was treated as a random factor with 4 levels, specimen (SP) was treated as random factor with 8 to 11 levels nested within LT and otolith ring (OR) was treated as a fixed factor with 7 levels, crossed to SP. This model-considering OR as a factor crossed to SP — was adopted as a solution for repeated measures (the repeated measure effect is removed by fitting it as a factor). For each light-trap, a means plot of the distance from the centroid for each otolith ring was used to show the change in fingerprint variability from Day 1 to Day 7.

The number of potential natal origins for postsettlers was investigated by analysing otolith core elemental concentrations (as a proxy for identifying the existence of single or multiple areas of origin; $\mathrm{Di}$ Franco et al. 2012) for a total of 230 individuals. A Mn:Ca spike, generally considered to be an indicator of the core location (Brophy et al. 2004, Ruttenberg et al. 2005), was not detected in most of the otolith cores analysed. For this reason, the centroid of the 3 core pits for each otolith was considered for subsequent analysis, as has been done in other species where the Mn:Ca spike appeared to be an ineffective 'core localizer' (Guidetti et al. 2013, Papetti et al. 2013). The similarity profile permutation procedure (SIMPROF; using the 'clustsig' package in R software) was carried out on the output of a cluster analysis (based on Ward's minimum variance hierarchical approach with Euclidean distance) to determine which clusters were significantly different at the $5 \%$ level. Similarity percentage (SIMPER; 'vegan' package in R) was used to assess which Element:Ca ratios mainly contributed to the differences among the significant clusters identified by the SIMPROF. The edge portion of post-settler otoliths (i.e. the post-settlement portion laid down just before capture) was analysed to assess the ability of the method to discriminate spatially distinct chemical signatures and validate post-settler otolith core analysis (Di Franco et al. 2012). PERMANOVA was used to test for differences among the 17 sampling sites, considering both the multi-elemental dataset and each Element:Ca ratio separately. In the 2 cases, site (SI) was treated as a random factor (17 levels), and otolith (OT) was treated as a random factor nested within SI (11 to 15 levels). There were 3 replicate ablations for each otolith (total $n=690$ ). Canonical analysis of principal coordinates (CAP; Anderson \& Willis 2003) and jackknife cross validation (\% of correct classifications) were also performed on the edge portion of the elemental data of post-settlers to assess how accurately the post-settlers were classified to the sites where they were collected. A specific randomization test (White \& Ruttenberg 2007) was used to estimate the probability that reclassification success (\% of correct classification) was better than random. In these analyses, the centroids of the 3 replicate sample pits for each specimen were calculated and used for CAP analysis.

Once different natal origins were identified (arbitrarily labeled as Sources A to G; see 'Results'), we investigated the post-settler replenishment patterns in the study area, testing for possible differences in zone and site replenishment for each identified natal source. With this aim, we ran a univariate 2-way PERMANOVA using natal origin as a variable (converted to numbers from 1 to 7 ). Zone (ZN) was treated as a random factor (3 levels); SI was treated as a random factor (5 to 6 levels) nested in $\mathrm{ZN}$. Finally, a Mantel test (based on $10^{4}$ permutations; 'ade4' package in $\mathrm{R}$ ) was performed to assess if sites that were close together were more likely to be 

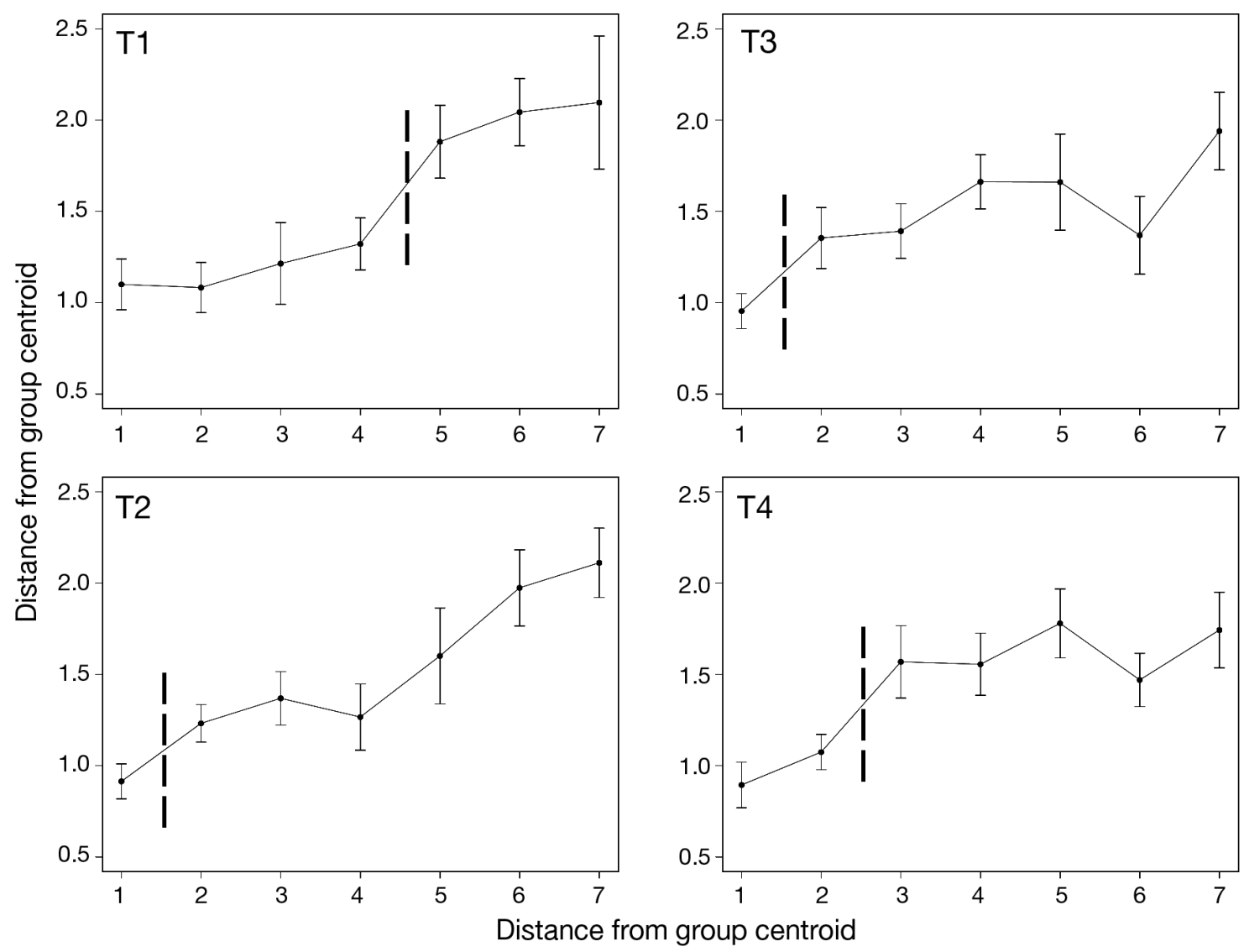

Fig. 2. Average $( \pm \mathrm{SE})$ distance from group centroid for each Oblada melanura otolith ring (day of life) analysed, as calculated by PERMDISP. Each plot represents a light-trap sample: T1 (10 specimens), T2 (8 specimens), T3 (11 specimens) and T4 (11 specimens). Vertical dashed segments identify significant differences in chemical fingerprint variability between pairs of consecutive rings

replenished by the same natal origin. Thus, we measured the correlation between the abundance of postsettlers coming from the same natal origin and the geographic distance between pairs of sites. The distance matrix of abundances was created considering the 17 sites as observations and the major natal sources identified as variables. Therefore, each site was associated with $n$ values of abundance, corresponding to the number of post-settlers coming from each of the $n$ major natal sources.

PERMANOVA and PERMDISP analyses were run using Primer v.6 PERMANOVA+ (Primer-E); all other analyses were run using R software (R Development Core Team 2014).

\section{RESULTS}

For the analysis of pre-settlers' patch cohesiveness, a significant difference in multivariate chemical composition variability between otolith rings (i.e. days of life) was detected (PERMANOVA, p < 0.01), with increasing variability from Days 1 to 7 (Fig. 2) for all 4 light-trap samples (where Day 1 is the sampling day and Day 7 is the 6th day before sampling). Pairwise comparisons between days indicated that statistically significant increments in chemical fingerprint variability were not simultaneous across light-trap samples (i.e. did not happen between the same pair of days across light-traps), resulting in the significant interaction LT $\times$ OT $(p<0.05)$ : for pre-settlers from light-trap $\mathrm{T} 4$, the first significant increment was recorded between the 2nd and 3rd ring, in $\mathrm{T} 1$ between the 4 th and 5th ring, while in T2 and T3 a significant increment was recorded between the 1st and 2 nd ring (where 1st ring is the most recent ring formed in the otolith) (Fig. 2).

Regarding the number of natal origins, the SIMPROF test segregated 7 statistically different clusters, i.e. core chemical fingerprints potentially corresponding to 7 different post-settler natal sources (Sources A to $G_{;}$Fig. 3). The 5 major sources (A, C, D, E and G) 


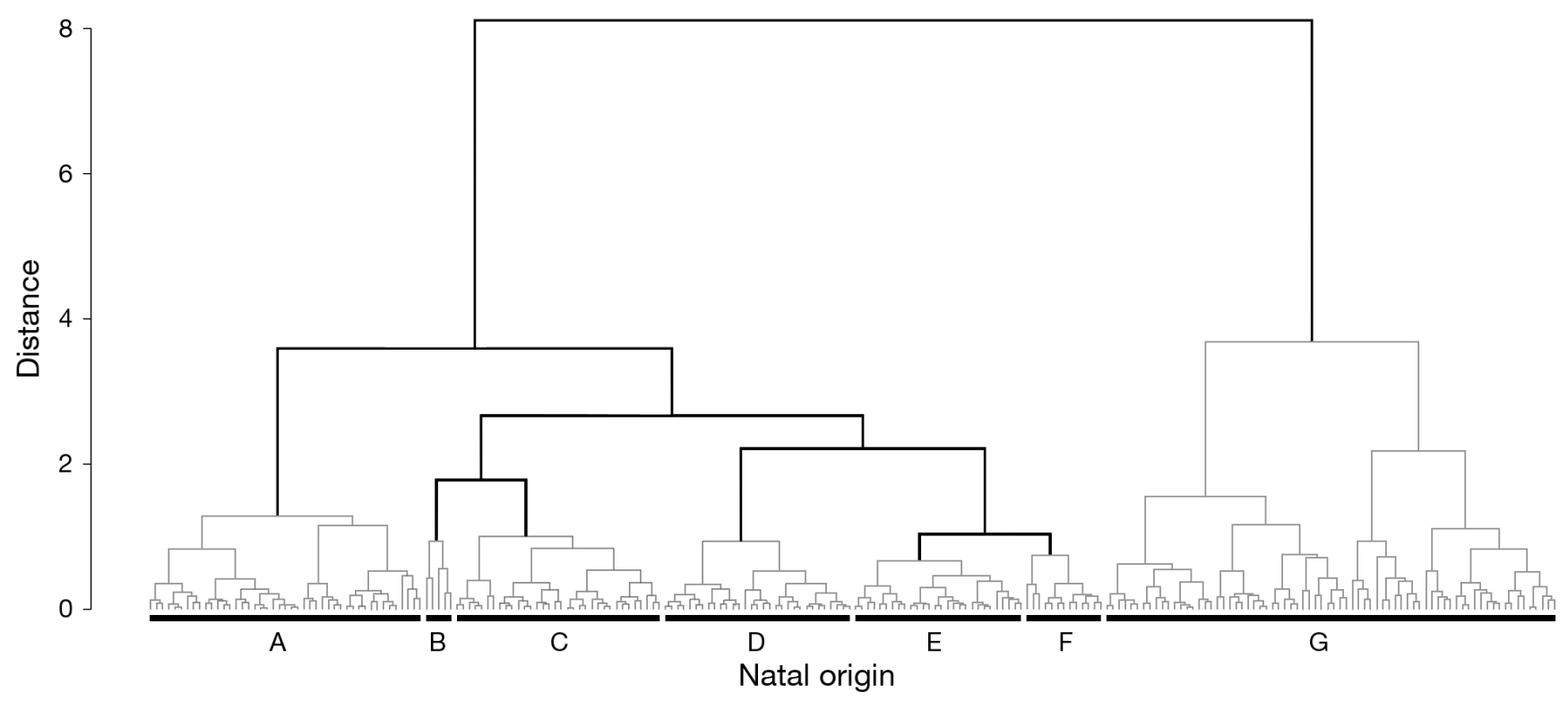

Fig. 3. Cluster (based on Ward's approach and Euclidean distances) of Oblada melanura post-settler otolith cores based on multivariate elemental concentrations (i.e. $\mathrm{Mg}: \mathrm{Ca}, \mathrm{Sr}: \mathrm{Ca}$ and $\mathrm{Ba}: \mathrm{Ca}$ ). Black branches: statistically significant groups determined from SIMPROF analysis (arbitrarily named from left to right); grey branches: non-significant differences

together accounted for $92.3 \%$ (212 individuals) of all the post-settlers, with single contributions ranging from 12.2 to $32.3 \%$. The remaining natal sources (B and F) contributed $2.1 \%$ (5 individuals) and 5.6\% (13 individuals), respectively. SIMPER analysis indicated that the Mg:Ca ratio contributed, on average, $50 \%$ of the total dissimilarity in pairwise comparisons among the 5 major natal sources identified, while $\mathrm{Ba}: \mathrm{Ca}$ and $\mathrm{Sr}: \mathrm{Ca}$ ratios contributed similar proportions to the remaining $50 \%$ of dissimilarity. Source G (which included 1/3 of all post-settlers) was characterized by a 2-fold concentration of Mg:Ca compared to the remaining clusters. Sources A and D showed lower values of Ba:Ca than C, E and G. Sr:Ca ratios were different among all 5 groups (Fig. 4). The chemical composition of the juvenile portion (edge) of post-settlers was significantly different among the 17 sampling sites in multi-elemental analysis (PERMANOVA, $\mathrm{p}<0.01$ ). Considering each Element:Ca ratio separately, 2 of the 3 elements investigated ( $\mathrm{Mg}$ and $\mathrm{Ba}$ ) showed significant differences among sites (PERMANOVA, Mg:Ca $\mathrm{p}<0.01, \mathrm{Ba}: \mathrm{Ca} \mathrm{p}<0.001$ ), while the $\mathrm{Sr}: \mathrm{Ca}$ ratio did not differ significantly between sites (see Fig. S1 in the Supplement at www. int-res.com/articles/suppl/m544p213_supp.pdf). Significant differences between otoliths were also found in both the multi-elemental analysis and the 3 univariate analyses ( $p<0.01$ for all tests), suggesting within-site differences among individuals. A significant jackknife reclassification success was found
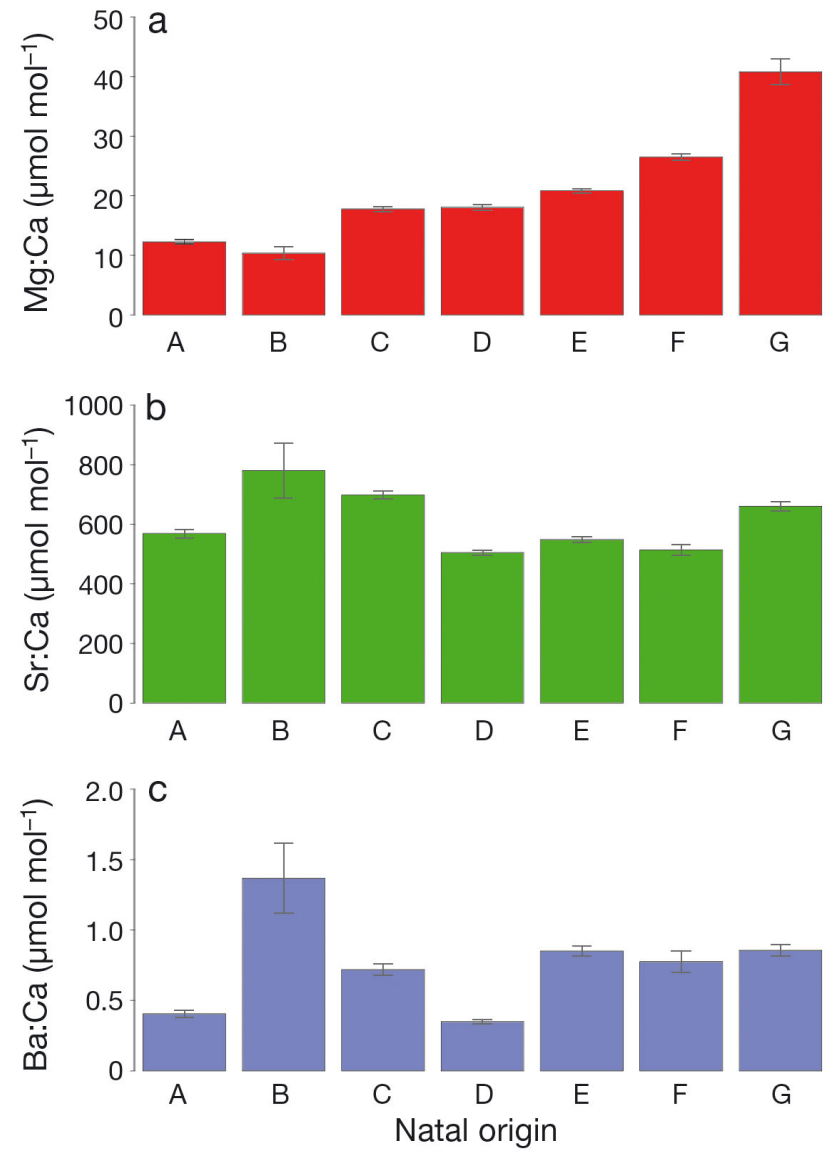

Fig. 4. Average ( $\pm \mathrm{SE}$ ) elemental ratios of (a) $\mathrm{Mg}: \mathrm{Ca}$, (b) $\mathrm{Sr}: \mathrm{Ca}$ and (c) $\mathrm{Ba}: \mathrm{Ca}$ in the core region of the clusters identified by SIMPROF (see Fig. 3) 


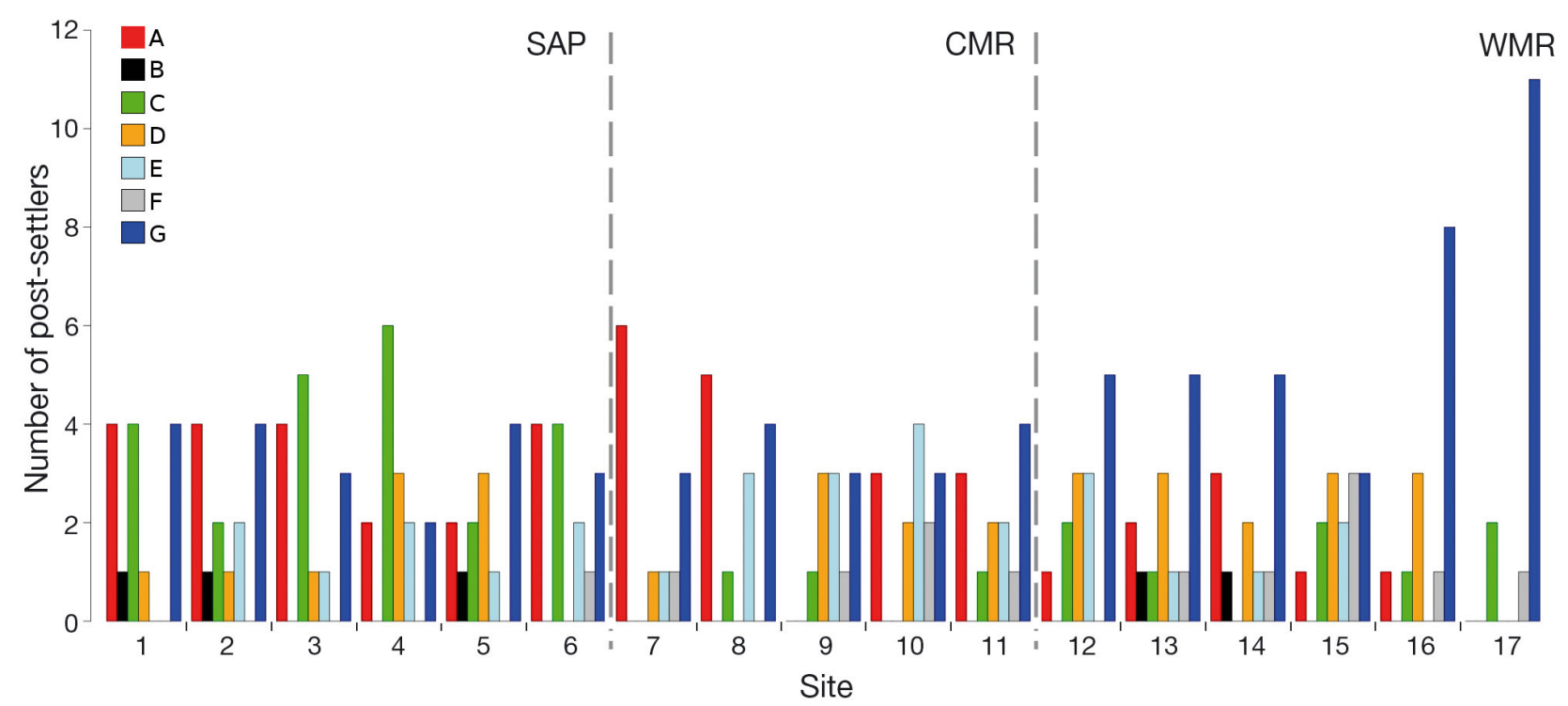

Fig. 5. Total number of Oblada melanura post-settlers from each sampling site (Sites 1-17), originating from each natal source (A-G) identified by SIMPROF, represented by colour. Sampling sites are numbered progressively from the northernmost to the southernmost region of the study area (see Fig. 1). Vertical dashed lines separate the 3 zones: southern Alicante province (SAP), central Murcia region (CMR) and western Murcia region (WMR) (see text for details)

(randomization test, $\mathrm{p}=0.002$ ) with $11.3 \%$ of postsettlers correctly classified to collection site in crossvalidation of CAP analysis $(5.8 \%$ correct classification to 1 of 17 sites due to chance alone) (Fig. S2 in the Supplement).

The post-settlement replenishment from the natal origins identified was found to be statistically different among the 3 zones (PERMANOVA, p < 0.01), with WMR (the southernmost zone) showing the greatest dissimilarity from SAP (the northernmost zone) (pairwise comparison, $\mathrm{p}<0.01$ ) and being only marginally different from CMR (the central zone) (pairwise comparison $\mathrm{p}<0.05$ ). No significant differences were found between SAP and CMR. No difference was detected at the site scale. The 5 major natal sources replenished, with different proportions, almost all sampling sites. Post-settlers from Source G were mainly found in WMR, with similar but lower abundances recorded in the other 2 zones. Source A similarly replenished SAP and CMR. Source C was mainly composed of individuals from sites contained in SAP (north of the study area). Individuals from Source E were mainly sampled in CMR, while a comparable number of post-settlers coming from Source D was found at each site (Figs. 1 \& 5). Regarding the last 2 natal sources, individuals from Source $F$ were found in WMR, CMR and the southernmost sampling site in SAP. Source B replenished 5 sites $(1,2,5,13$ and 14), with 1 ind. site ${ }^{-1}$. The abundance of post-settlers sharing the same natal origin, and the geographic distance between sampling sites were signif- icantly positively correlated (Mantel test, $\mathrm{r}=0.38, \mathrm{p}=$ 0.0001), indicating that geographically closer sites had on average higher abundances of post-settlers coming from the same natal origin than distant sites. Focusing on Sources G, A and C (the 3 major natal sources clustered together, representing more than $2 / 3$ of all post-settlers), the 2 higher values of postsettler abundance from each source were recorded in pairs of adjacent and nearest sites (Sites 17 and 16 for Source G, Sites 7 and 8 for Source A and Sites 3 and 4 for Source C), while lower values were recorded at all other sites (Fig. 5).

\section{DISCUSSION}

For most marine fish, the pelagic phase before settlement represents a critical period of dispersal, shaping connectivity patterns between populations (Burgess et al. 2014, but see Di Franco et al. 2015). Thus, knowledge about species dispersal characteristics (e.g. number of natal origins, dispersal distances) is crucial for understanding fish population dynamics and connectivity. This information can ultimately aid in the design of more effective marine protection strategies (Pujolar et al. 2013, Di Franco et al. 2015, Green et al. 2015). In this study, we analysed otolith chemical composition of the early life stages of Oblada melanura in order to provide information on the dispersal characteristics of its propagule pelagic phase in the south-western Mediterranean Sea. 
Analysis of larval patch cohesiveness suggests that groups of larvae can merge in the pelagic environment after having travelled separately for some days. Recent work demonstrated a similar larval patch formation in a small triplefin fish from New Zealand reefs, using otolith chemical analysis (Shima \& Swearer 2009, Shima et al. 2015). However, cases of protracted larval patch cohesiveness have also been documented, with larvae travelling on the same dispersal pathway for the entire pelagic phase (Ben-Tzvi et al. 2012, Bernardi et al. 2012). In our study, increased otolith chemical variability was recorded between the day of sampling and the day immediately prior to that, from specimens captured in 2 lighttraps, suggesting that during the sampling night 2 or more discrete groups of larvae were attracted toward the same trap after having travelling along different dispersal pathways. In the other 2 light-traps, stable chemical compositions between sampling days were observed, suggesting that the aggregation of distinct patches can occur at different times during the larval phase. It is difficult to establish if this aggregation tendency is a result of larval behaviour or particular oceanic features (e.g. gyres) that can mix together patches that were previously separated. Kiparissis et al. (2008) also found evidence of aggregation in postsettlement individuals of $O$. melanura, a behaviour that was not observed in other Mediterranean sparid fishes (Harmelin-Vivien et al. 1995). In particular, post-settlers arrive in small shoals and then actively aggregate into larger shoals with increasing fish size after various aggregation steps (Kiparissis et al. 2008). From this perspective, the same aggregation behaviour could characterize the larval phase, determining a mix of distinct larval patches, potentially originating from different natal sources, during the pelagic phase. This patch-mixing tendency could be an adaptive strategy that would guarantee a higher genetic diversity, and thus higher survival probability when faced with environmental uncertainty in the settlement habitat and its associated high mortality rates (Nanninga \& Berumen 2014, Shima et al. 2015). In light of these considerations, it is evident that the diversity in post-settler natal sources we recorded at each sampling site could be a consequence of multiple aggregation steps that occurred both during the propagule dispersal phase and soon after the settlement process. Together, these could contribute to demographic heterogeneity, which is fundamental in driving meta-population dynamics and the persistence of species (Kritzer \& Sale 2004).

Our analysis of post-settler core elemental composition indicated the presence of multiple sources of propagules, replenishing several sampling sites in different proportions along the south-eastern coast of Spain. Recent work carried out in the eastern Atlantic and the Mediterranean Sea produced similar results, with a high diversity of natal sources evident in early post-settler individuals sampled at coastal sites (Fontes et al. 2009, Di Franco et al. 2012, 2015). The significant spatial variability in chemical composition of the juvenile portion (i.e. otolith edge) of postsettler otoliths was corroborated by the reclassification success (being significantly higher than random) of post-settlers to their sampling sites. These outcomes highlight the ability of the method used to discriminate spatially distinct chemical signatures at the spatio-temporal scale analysed, allowing us to reasonably draw inferences on the core portion. The segregation of different core chemical signatures is likely related to spatial differences in the chemicalphysical characteristics of the water masses in which spawning occurred. Different chemical fingerprints in otolith cores could also be associated with temporal variability in the characteristics of water masses associated with temporally distinct spawning events. Otolith micro-structural analysis carried out on the same specimens analysed in this study showed that in 2013 the study area was replenished by simultaneous spawning events that occurred over a period of 2 wk (Calò et al. unpubl. data), so we can confidently assume that the different chemical fingerprints recorded are unlikely a consequence of a temporal variation.

The methodology used here does not allow us to geographically locate the natal origins identified, impeding knowledge of the exact range and frequency distribution (i.e. kernel) of larval dispersal distances. However, it allows estimation of the spatial scale over which dispersal can occur in the area. All the sites, located along $\sim 180 \mathrm{~km}$ of coast, were supplied by multiple natal sources. This information allows us to infer that the most conservative value of maximum dispersal distance is $\sim 90 \mathrm{~km}$ (i.e. half of the length of coast in the study area). In fact, supposing the case in which 2 of the natal sources identified were adjacent and at the centre of the study area, propagules would have travelled at least $90 \mathrm{~km}$. In all other cases, the dispersal distance would be greater. This estimate of propagule dispersal distance is in accordance with the results of other studies conducted on other sparid species in the Mediterranean Sea using otolith natural tags (Di Franco et al. 2012, 2015), and in general are within the range of propagule dispersal suggested for other temperate fish species (Anadón et al. 2013). Additional information from complementary 
approaches (for example, biophysical larval dispersal models or larval behaviour studies) are needed to corroborate the estimate of dispersal distance found for O. melanura in our study area. Recent work conducted in the north-western Mediterranean Sea found that $O$. melanura larvae can have surprisingly high swimming capabilities, with critical velocities $>13 \mathrm{~cm} \mathrm{~s}^{-1}$ (the average current speed recorded for the same sector of the Mediterranean Sea; Faillettaz 2015). Thus, although the pelagic larval duration (PLD) of the saddled sea bream is relatively short compared to other Mediterranean coastal fishes (Macpherson \& Raventós 2006, Di Franco et al. 2013), the swimming capacity of the species could be a possible explanation for the rapid propagule dispersal from their spawning grounds to settlement habitats.

Even though it was not possible to locate the natal sources, our results suggest that the pattern of larval supply to the sites we sampled has a certain spatial dependence. Post-settlers from the same natal origin were more frequently found at sites that were closer together, with the highest abundances of postsettlers coming from the same origin recorded in pairs of adjacent sites, and lower values at all other sites within the study area. This output was consistent among almost all the major natal origins identified. Moreover, although the major natal origins supplied almost all the sampling sites, significant differences in post-settler replenishment was recorded among the 3 zones differentiated in our study area, suggesting that post-settler demographic composition can change at a scale of 50 to $100 \mathrm{~km}$. A similar result was found by Fontes et al. (2009), who analysed otolith core composition in the temperate wrasse Coris julis from the Azores archipelago. The spatial difference in natal source composition between the northernmost (SAP) and southernmost (WMR) zones in our study is also in accordance with a significant difference in the PLD of $O$. melanura detected between zones: the mean PLD of specimens used in this study was statistically lower in SAP than in WMR (Calò et al. unpubl. data). This concordant result could indicate that the geographic origin of propagules and early life history traits (e.g. PLD) could have a common source of variability or be nonindependent. Patterns of post-settler distribution along the coast are likely to be a consequence of preand/or post-settlement mechanisms as well as both biological (e.g. behaviour, inter- and intra-specific competition for food and space, mortality) and physical (i.e. current dynamics during the larval dispersal phase) processes. From this perspective, the large difference in natal origin composition found between
WMR and SAP, and the weak, but significant, difference found between WMR and CMR could be a consequence of the mesoscale oceanographic pattern that characterizes the region. Rossi et al. (2014) pointed out that the separation between the Alboran Sea and the rest of the Mediterranean Sea, generally thought to be along the Almeria-Oran front, could actually have its Spanish coastal extreme around Cabo de Palos, which is located in the CMR zone in our study area (Fig. 1). The presence of this oceanographic boundary, already suggested to be a biogeographical barrier in the Western Mediterranean Sea (Pérez-Ruzafa 2010), could reduce the dispersal of propagules from the WMR zone toward the northernmost zones, and vice versa. However, it is difficult to draw conclusions regarding the forces that determined the spatially dependent outcomes recorded in this study, since the information necessary to elucidate them is unavailable, especially considering the lack of information on fish spawning grounds for the studied species. Thus, further investigations are required, using other methodologies that would permit direct tracking of propagule movements from source to settlement site. These methods (e.g. otolith artificial tagging or genetic parentage analysis), although undoubtedly powerful, have been rarely applied thus far in the Mediterranean context, given the lack of spawning ground location data and the huge sampling effort required to obtain representative results (Calò et al. 2013).

To conclude, the present study provides insights into the propagule dispersal traits of a temperate coastal fish. This is the first study to estimate such dispersal distances in the south-western Mediterranean Sea and, to our knowledge, the first to provide information on larval patch dispersal cohesiveness during the pelagic phase of a Mediterranean coastal fish. Information on propagule dispersal patterns is vital to support planning of MPAs, and especially for the implementation of effective MPA networks (Planes et al. 2009, Gaines et al. 2010). From this perspective, our results are particularly relevant considering the environmental values of the region, and the strong effort that is being put forth to build an effective network of MPAs in the sector of the Mediterranean Sea considered here. Although the study of a single species is insufficient to make generalisations on the spatial arrangement for effective MPAs, it does provide a valid contribution to this field. Together with information on other species and/or using different approaches, this information can provide the necessary background for effective marine spatial conservation actions. 
Acknowledgements. This research was supported by the European project 'Training Network for Monitoring Mediterranean Marine Protected Areas' (MMMPA: FP7PEOPLE-2011-ITN) [grant number 290056]. The authors thank Professor Robert K. Clarke (Plymouth University) for his invaluable advice and assistance with statistical analyses; Felio Lozano and his team, Diego Martínez Díaz, Manuel Muntoni and Chiara Adamuccio for invaluable help during fieldwork; and Katie E. Hogg (University of Murcia) for English editing. The authors also thank the editor and 2 anonymous reviewers for their useful comments which helped improve the manuscript.

\section{LITERATURE CITED}

Anadón JD, Mancha-Cisneros M, Best B, Gerber LR (2013) Habitat-specific larval dispersal and marine connectivity: implications for spatial conservation planning. Ecosphere 4

Anderson MJ, Willis TJ (2003) Canonical analysis of principal coordinates: a useful method of constrained ordination for ecology. Ecology 84:511-525

Antolovi N, Kozul V, Safner R, Glavi N, Bolotin J (2010) Embryonic and yolk-sac larval development of saddled bream, Oblada melanura (Sparidae). Cybium 34: 381-386

> Barbee N, Swearer S (2007) Characterizing natal source population signatures in the diadromous fish Galaxias maculatus, using embryonic otolith chemistry. Mar Ecol Prog Ser 343:273-282

Barnett-Johnson R, Pearson TE, Ramos FC, Grimes CB, MacFarlane RB (2008) Tracking natal origins of salmon using isotopes, otoliths, and landscape geology. Limnol Oceanogr 53:1633-1642

Bauchot ML, Hureau JC (1986) Sparidae. In: Whitehead PJP, Bauchot ML, Hureau JC, Nielsen J, Tortonese E (eds) Fishes of the north-eastern Atlantic and the Mediterranean, Vol 2. UNESCO, Paris, p 883-907

Ben-Tzvi O, Abelson A, Gaines SD, Bernardi G and others (2012) Evidence for cohesive dispersal in the sea. PLoS ONE 7:e42672

Bernardi G, Beldade R, Holbrook SJ, Schmitt RJ (2012) Fullsibs in cohorts of newly settled coral reef fishes. PLoS ONE 7:e44953

> Berumen ML, Walsh HJ, Raventos N, Planes S, Jones GP, Starczak V, Thorrold SR (2010) Otolith geochemistry does not reflect dispersal history of clownfish larvae. Coral Reefs 29:883-891

> Brophy D, Jeffries TE, Danilowicz BS (2004) Elevated manganese concentrations at the cores of clupeid otoliths: possible environmental, physiological, or structural origins. Mar Biol 144:779-786

Burgess SC, Nickols KJ, Griesemer CD, Barnett LK and others (2014) Beyond connectivity: how empirical methods can quantify population persistence to improve marine protected-area design. Ecol Appl 24:257-270

Bussotti S, Guidetti P (2011) Timing and habitat preferences for settlement of juvenile fishes in the Marine Protected Area of Torre Guaceto (south-eastern Italy, Adriatic Sea). Ital J Zool 78:243-254

Calò A, Félix-Hackradt FC, Garcia J, Hackradt CW, Rocklin D, Treviño Otón J, García Charton JA (2013) A review of methods to assess connectivity and dispersal between fish populations in the Mediterranean Sea. Adv
Oceanogr Limnol 4:150-175

Calvin-Calvo JC, Franco Navarra I, Marín Atucha A, Belmonte Ríos A, Ruiz Fernandez JM (1999) El litoral sumergido de la Región de Murcia. Cartografía bionómica y valores ambientales. Dirección General del Medio Natural, Conserjería de Medio Ambiente y Ordenación del Territorio, Región de Murcia

Campana SE (1999) Chemistry and composition of fish otoliths: pathways, mechanisms and applications. Mar Ecol Prog Ser 188:263-297

Cote J, Clobert J, Brodin T, Fogarty S, Sih A (2010) Personality-dependent dispersal: characterization, ontogeny and consequences for spatially structured populations. Philos Trans R Soc Lond B Biol Sci 365:4065-4076

> Di Franco A, Gillanders BM, De Benedetto G, Pennetta A, De Leo GA, Guidetti P (2012) Dispersal patterns of coastal fish: implications for designing networks of Marine Protected Areas. PLoS ONE 7:e31681

> Di Franco A, Qian K, Calò A, Di Lorenzo M, Planes S, Guidetti P (2013) Patterns of variability in early life traits of a Mediterranean coastal fish. Mar Ecol Prog Ser 476: $227-235$

> Di Franco A, Bulleri F, Pennetta A, De Benedetto G, Clarke KR, Guidetti P (2014) Within-otolith variability in chemical fingerprints: implications for sampling designs and possible environmental interpretation. PLoS ONE 9: e101701

> Di Franco A, Calò A, Pennetta A, De Benedetto G, Planes S, Guidetti P (2015) Dispersal of larval and juvenile seabream: implications for Mediterranean marine protected areas. Biol Conserv 192:361-368

Faillettaz R (2015) Estimation des capacités comportementales des larves de poissons et leurs implications pour la phase larvaire: un cas d'étude d'espèces démersales de Méditerranée nord-occidentale. PhD thesis, Université Pierre et Marie Curie, Paris

Félix-Hackradt FC, Hackradt CW, Treviño-Otón J, SegoviaViadero M, Pérez-Ruzafa A, García-Charton JA (2013) Environmental determinants on fish post-larval distribution in coastal areas of south-western Mediterranean Sea. Estuar Coast Shelf Sci 129:59-72

> Félix-Hackradt FC, Hackradt CW, Treviño-Otón J, PérezRuzafa A, García-Charton JA (2014) Habitat use and ontogenetic shifts of fish life stages at rocky reefs in south-western Mediterranean Sea. J Sea Res 88:67-77

Fontes J, Caselle J, Sheehy M, Santos R, Warner R (2009) Natal signatures of juvenile Coris julis in the Azores: investigating connectivity scenarios in an oceanic archipelago. Mar Ecol Prog Ser 387:51-59

Gaines SD, White C, Carr MH, Palumbi SR (2010) Designing marine reserve networks for both conservation and fisheries management. Proc Natl Acad Sci USA 107: 18286-18293

García-Charton JA, Pérez-Ruzafa Á, Sánchez-Jerez P, Bayle-Sempere JT, Re ones O, Moreno D (2004) Multiscale spatial heterogeneity, habitat structure, and the effect of marine reserves on Western Mediterranean rocky reef fish assemblages. Mar Biol 144:161-182

Giannossa LC, Fico D, Pennetta A, Mangone A, Laviano R, De Benedetto GE (2015) Integrated investigations for the characterisation of Roman lead-glazed pottery from Pompeii and Herculaneum (Italy). Chem Pap 69: 1033-1043

Green BS, Mapstone BD, Carlos G, Begg GA (2009) Tropical fish otoliths: information for assessment, management 
and ecology. Springer, New York, NY

Green AL, Maypa AP, Almany GR, Rhodes KL and others (2015) Larval dispersal and movement patterns of coral reef fishes, and implications for marine reserve network design. Biol Rev 90:1215-1247

Grüss A, Kaplan DM, Guénette S, Roberts CM, Botsford LW (2011) Consequences of adult and juvenile movement for marine protected areas. Biol Conserv 144:692-702

Guidetti P, Petrillo M, De Benedetto G, Albertelli G (2013) The use of otolith microchemistry to investigate spawning patterns of European anchovy: a case study in the eastern Ligurian Sea (NW Mediterranean). Fish Res 139: $1-4$

Hamilton SL, Regetz J, Warner RR (2008) Post-settlement survival linked to larval life in a marine fish. Proc Natl Acad Sci USA 105:1561-1566

> Harmelin-Vivien M, Harmelin JG, Leboulleux V (1995) Microhabitat requirements for settlement of juvenile sparid fishes on Mediterranean rocky shores. Hydrobiologia 300/301:309-320

Kiparissis S, Tserpes G, Somarakis S, Economidis PS, Koutsikopoulos C (2008) Site-attachment behaviour of Oblada melanura (Linnaeus, 1758) (Osteichthyes: Sparidae) benthic larvae: a quantitative approach. Sci Mar 72 : 429-436

Kritzer JP, Sale PF (2004) Metapopulation ecology in the sea: from Levins' model to marine ecology and fisheries science. Fish Fish 5:131-140

Leary S, Underwood W, Anthony R, Cartner S and others (2013) AVMA guidelines for the euthanasia of animals: 2013 edition. American Veterinary Medical Association, Schaumburg, IL

Leis JM (2015) Is dispersal of larval reef fishes passive? In: Mora C (ed) Ecology of fishes on coral reefs. Cambridge University Press, Cambridge, p 223-226

Leis JM, van Herwerden L, Patterson HM (2011) Estimating connectivity in marine fish populations: What works best? Oceanogr Mar Biol Annu Rev 49:193-234

Lloret J, Zaragoza N, Caballero D, Font T, Casadevall M, Riera V (2008) Spearfishing pressure on fish communities in rocky coastal habitats in a Mediterranean marine protected area. Fish Res 94:84-91

Macpherson E, Raventós N (2006) Relationship between pelagic larval duration and geographic distribution of Mediterranean littoral fishes. Mar Ecol Prog Ser 327: 257-265

Miller JA, DiMaria RA, Hurst TP (2014) Patterns of larval source distribution and mixing in early life stages of Pacific cod (Gadus macrocephalus) in the southeastern Bering Sea. Deep-Sea Res II, doi:10.1016/j.dsr2.2014. 12.012

Muhlfeld CC, Thorrold SR, McMahon TE, Marotz B, Gillanders B (2012) Estimating westslope cutthroat trout (Oncorhynchus clarkiilewisi) movements in a river network using strontium isoscapes. Can J Fish Aquat Sci 69: 906-915

Editorial responsibility: Alejandro Gallego, Aberdeen, UK
Nanninga GB, Berumen ML (2014) The role of individual variation in marine larval dispersal. Front Mar Sci 1:1-17

Papetti C, Di Franco A, Zane L, Guidetti P and others (2013) Single population and common natal origin for Adriatic Scomber scombrus stocks: evidence from an integrated approach. ICES J Mar Sci 70:387-398

Pérez-Ruzafa Á (2010) Project final memory. Coastal Oeanographic Observatory of Murcia, Murcia

Planes S, Jones GP, Thorrold SR (2009) Larval dispersal connects fish populations in a network of marine protected areas. Proc Natl Acad Sci USA 106:5693-5697

Pujolar JM, Schiavina M, Di Franco A, Melià P and others (2013) Understanding the effectiveness of marine protected areas using genetic connectivity patterns and Lagrangian simulations. Divers Distrib 19:1531-1542

R Core Team (2014) R: a language and environment for statistical computing. R Foundation for Statistical Computing, Vienna. Available at http://www.R-project.org/

Raventós N, Macpherson E (2001) Planktonic larval duration and settlement marks on the otoliths of Mediterranean littoral fishes. Mar Biol 138:1115-1120

Rossi V, Ser-Giacomi E, López C, Hernández-García E (2014) Hydrodynamic provinces and oceanic connectivity from a transport network help designing marine reserves. Geophys Res Lett 41:2883-2891

Ruttenberg B, Hamilton S, Hickford M, Paradis G and others (2005) Elevated levels of trace elements in cores of otoliths and their potential for use as natural tags. Mar Ecol Prog Ser 297:273-281

Ruttenberg BI, Hamilton SL, Warner RR (2008) Spatial and temporal variation in the natal otolith chemistry of a Hawaiian reef fish: prospects for measuring population connectivity. Can J Fish Aquat Sci 65:1181-1192

Sandin SA, Regetz J, Hamilton SL (2005) Testing larval fish dispersal hypotheses using maximum likelihood analysis of otolith chemistry data. Mar Freshw Res 56:725-734

Shima JS, Swearer SE (2009) Larval quality is shaped by matrix effects: implications for connectivity in a marine metapopulation. Ecology 90:1255-1267

Shima JS, Swearer SE (2010) The legacy of dispersal: larval experience shapes persistence later in the life of a reef fish. J Anim Ecol 79:1308-1314

Shima JS, Noonburg EG, Swearer SE (2015) Consequences of variable larval dispersal pathways and resulting phenotypic mixtures to the dynamics of marine metapopulations. Biol Lett 11:20140778

Standish JD, Sheehy M, Warner RR (2008) Use of otolith natal elemental signatures as natural tags to evaluate connectivity among open-coast fish populations. Mar Ecol Prog Ser 356:259-268

- Walther B, Thorrold S (2006) Water, not food, contributes the majority of strontium and barium deposited in the otoliths of a marine fish. Mar Ecol Prog Ser 311:125-130

White JW, Ruttenberg BI (2007) Discriminant function analysis in marine ecology: some oversights and their solutions. Mar Ecol Prog Ser 329:301-305

Submitted: August 10, 2015; Accepted: January 12, 2016 Proofs received from author(s): February 8, 2016 